\title{
As letras e a nação: Olavo Bilac e suas crônicas sobre educação (1900-1906)
}

The letters and the nation: Olavo Bilac and his cronicles about education (1900-1906)

Las letras e la nación: Olavo Bilac e sus cronicas sobre educación (1900-1906)

\author{
Felipe Yera Barchi \\ Prefeitura Municipal de Paraguaçu Paulista, São Paulo \\ https://orcid.org/0000-0002-0156-1876 \\ http://lattes.cnpq.br/9147137881055201 \\ felipeyerabarchi@gmail.com \\ Fabiana Lopes da Cunha \\ Universidade Estadual Paulista Júlio de Mesquita Filho, Brasil \\ https://orcid.org/0000-0003-1005-3248 \\ http://lattes.cnpq.br/5376659157733801 \\ fabianalopesdacunha@gmail.com
}

\section{Resumo}

Ofuscadas por sua poesia, as crônicas de Olavo Bilac são importantes documentos para análise dos debates políticos, sociais e educacionais na Primeira República. Ocupando espaço de prestígio nos jornais brasileiros da Belle Époque Bilac engajou-se em prol de uma agenda modernizante na qual a alfabetização massiva da população desempenhava tarefa primordial. O letramento era visto como a pedra de toque capaz de conduzir o Brasil à moderna civilização.

Palavras-chave: Olavo Bilac. Educação. Analfabetismo. Crônicas. 


\begin{abstract}
Obfuscated by his poetry, the chronicles of Olavo Bilac are important documents for the analysis of political, social and educational debates in the First Braziliam Republic. Occupying a space of prestige in the Brazilian newspapers of the Belle Époque Bilac engaged itself in a modernizer agenda which the massive literacy of the population played a primordial task. Literacy was seen as the touchstone able of leading Brazil to modern civilization.
\end{abstract}

Keywords: Olavo Bilac. Education. Ileteracy. Cronicles.

\title{
Resúmem
}

Ofuscadas por su poesía, las crónicas de Olavo Bilac son importantes documentos para el análisis de los debates políticos, sociales y educativos en la Primera República. Ocupando espacio de prestigio en los periódicos brasileños de la Belle Époque Bilac se comprometió en pro de una agenda modernizante en la que la alfabetización masiva de la población desempeñaba una tarea primordial. El letramento era visto como la piedra de toque capaz de conducir a Brasil a la moderna civilización.

Palabras-clave: Olavo Bilac. Educación. Analfabetismo. Crônicas. 


\section{Introdução}

Olavo Bilac (1865-1918) notabilizou-se aos olhos do grande público como poeta desde muito cedo com o lançamento da Via Láctea (1887). No entanto, convém destacar que sua atuação no mundo das letras foi ampla e polivalente. Atuou como ghost-writter, publicitário, escreveu livros infantis, manuais escolares, e também crônicas. Neste último gênero, sucedeu a ninguém menos que Machado de Assis (1839-1908) na Gazeta de Notícias - um dos mais importantes jornais do Brasil naquele momento. As crônicas de Bilac revelam-se ricos documentos para análise dos debates políticos, sociais e educacionais travados durante a Primeira República (1889-1930). Em linhas gerais, seu período mais fértil como cronista está centrado entre os anos de 1897 e 1908: a primeira baliza refere-se ao ano em que assumiu essa tarefa na Gazeta; a segunda, marca a definitiva ruptura perante a imprensa - embora seu engajamento público só tenha aumentado depois disso ${ }^{1}$.

Pode-se observar o papel de destaque desempenhado por Bilac como epígono de ideias pedagógicas que configuram um ideário educacional dos mais longevos na história da educação brasileira. O poeta desceu do altar das musas para envergar sua pena em prol de um projeto de modernização do país que via a difusão do letramento desempenhar aspecto essencial para o seu progresso. Esse processo que Nicolau Sevcenko chamou de "a inserção compulsória do Brasil na Belle Époque" (SEVCENKO, 2003, p. 35), foi defendido com veemência por Bilac em suas múltiplas arestas, quais sejam: saneamento, embelezamento da capital, vacinação obrigatória e instrução. Até mesmo os efeitos colaterais - revolta da vacina, demolição do casario colonial e gentrificação - que estavam no bojo dessas "benesses modernas" foram minimizados ou mesmo justificados por Bilac. Como inspetor da instrução pública da prefeitura do Rio de Janeiro e homem de letras que foi, não é de se espantar que Bilac tenha privilegiado a alfabetização como pauta principal dessa agenda modernizante.

\section{Analfabetismo: o inimigo a ser combatido}

Para Bilac a alfabetização era a questão vital do Brasil. Ao contrário de outros intelectuais da época que viam a questão racial ou da composição étnica do tipo nacional como o problema fundamental do país ${ }^{2}$, o poeta e cronista estabelecia com muita clareza o inimigo número um da pátria: o analfabetismo, a "causa principal, e talvez única, de todo nosso atraso" (Gazeta de Notícias, 04/12/1903 in BILAC, 2011, p. 202). À despeito de concentrar os grandes nomes da intelligentsia nacional, bem como a massa dos letrados comuns, o Rio de Janeiro era uma cidade de analfabetos e, se essa era a realidade da capital nacional, "imaginai o que haverá nos Estados!" (Gazeta de Notícias, 03/02/1902 in BILAC, 2011, p.135) - indagava o cronista. Ainda nessa mesma crônica de 1902, indignado, seguia protestando contra o fechamento de escolas:

Exceção feita do Rio Grande do Sul e de São Paulo, onde a instrução pública tem merecido cuidados especiais, o analfabetismo domina toda a vastidão do Brasil. Fecham-se escolas 'por falta de frequência'. E ninguém se lembra de que, em vez de fechar escolas, o dever dos

\footnotetext{
1 Após uma polêmica que envolveu anúncios governamentais publicados na Agência de Notícias América (propriedade de Bilac e Martins Fontes) pela quantia assombrosa à época de 27 contos de réis o poeta e cronista interrompe sua colaboração nos jornais em que atuava e promete nunca mais escrever para imprensa (BILAC, 2011, p. 41). A promessa foi cumprida e após esse episódio Bilac viria a concentrar esforços na escrita de livros infantis e escolares (Através do Brasil e A Pátria Brasileira são desse tempo), em campanhas como a do serviço militar obrigatório (1915), e também pela expansão da alfabetização.

${ }^{2}$ Silvio Romero (1851-1914), João Ribeiro (1860-1934) e Nina Rodrigues (1862-1906), por exemplo.
} 
governos é obrigar o povo a frequentá-las (Gazeta de Notícias, 03/02/1902 in BILAC, 2011, p. 135).

Transitando entre a capital nacional e as capitais do mundo, especialmente Paris ${ }^{3}$, Bilac tomava o horizonte europeu como referência e via o letramento da população como condição sine qua non para que o país adentrasse a modernidade. No seu entender, a instrução primária deveria ser obrigatória aqui como já havia se tornado nos "países civilizados". Segundo Bilac, o Brasil contava o maior número de analfabetos entre os países da América e o fechamento de escolas por falta de frequência era um disparate "porque o povo é relaxado, porque os marmanjos se dão bem com a ignorância, porque ninguém obriga a criança a ir à escola" (idem, ibidem) e não pelo fato do percentual de alfabetizados ser satisfatório. Na agenda proposta pelo escritor, a obrigatoriedade da instrução primária funcionava como uma espécie de imperativo categórico kantiano:

"Obrigatória"... a palavra é dura, e não falta quem se revolte contra o que ela exprime. Mas há casos em que o respeito a liberdade individual é um absurdo. Tem alguém o direito de andar nu, pelas ruas? Ou de praticar atos indecentes praça pública? [...] Pois o analfabetismo é também uma indecência, uma imoralidade, um perigo público. Por causa dele, é que não há no Brasil estatísticas, nem eleições, nem dignidade cívica, nem sentimento de nacionalidade (Gazeta de Notícias, 03/02/1902 in BILAC, 2011, p. 135).

Mais adiante, quando se aproximava a tão desejada decretação de uma lei federal obrigando os estados a providenciarem instrução primária obrigatória, Bilac ironiza os "defensores da liberdade" que advogavam o direito de não tomar vacina e de não ministrar educação às crianças invocando - supostamente - ideais liberais. Com humor, escrevia o cronista:

Nós vivemos a exaltar a Constituição da Suíça, os costumes da Suíça, a moralidade da Suíça, o sistema eleitoral da Suíça, as virtudes cívicas da Suíça, a liberdade da Suíça, e, sempre que queremos citar uma repúblicamodelo, citamos a Suíça. Pois bem: a medida lembrada pelo Sr. Leôncio de Carvalho é copiada de um artigo da Constituição dessa liberalíssima Suíça. Aquele povo, que ama sobre todas as coisas a Liberdade, não reconhece a liberdade do analfabetismo...Eis aí o que vai esfriar talvez o entusiasmo dos nossos liberais pela gloriosa Helvécia! (Gazeta de Notícias, 19/12/1903 in BILAC, 2011, p. 207).

Erradicar o analfabetismo significava complementar o trabalho iniciado com a abolição da escravatura e a proclamação da República: "Como pode ser livre e saber o que é liberdade quem não sabe ler, quem tem o espírito fechado a todas as conquistas modernas, quem deixa a sua inteligência abastardar-se e aviltar-se pela inação até ficar reduzida a um simples instinto tateante e titubeante?" (idem, ibidem). A consequência do iletramento como regra social acabava, na visão de Bilac, por empobrecer o país em diversas áreas e, no âmbito de seu métier, tornar o país e sua literatura obscuras tanto aqui como no exterior.

\footnotetext{
${ }^{3}$ Bilac viajou diversas vezes à Europa e Paris era sua parada favorita. Esteve lá pela primeira vez entre 1890 e 1891, em 1904, e de 1906 em diante quase anualmente (JORGE, 1992).
} 
Triste país este, em que não há jornal que venda cinquenta mil exemplares por dia, em que não há livro de que se esgote uma edição por ano, em que não há escritor que possa viver unicamente com o produto do seu trabalho intelectual! E ainda nos queixamos da obscuridade em que vivemos! $\mathrm{E}$ ainda lamentamos que ninguém nos conheça! (Gazeta de Notícias, 11/02/1903 in BILAC, 2011, p. 170).

O triste cenário da alfabetização no país não era mera questão de política cultural ou educacional, era também uma questão de segurança nacional. Aqui e acolá surgiam notícias sensacionalistas como "O Perigo Alemão", "O Perigo Americano", "O Perigo Japonês" e congêneres. Estes "perigos" significavam a multiplicação de escolas estrangeiras pelo Brasil e a virtual estrangeirização de algumas regiões do país. Para Bilac, havia certo risco na medida em que "um povo de cem milhões de analfabetos é conquistado em dois tempos por um povo com um milhão de homens instruídos" (Gazeta de Notícias, 26/02/1904 in BILAC, 2011, p. 230) - e a experiência neocolonial bem demonstrava a verdade dessa afirmação. Citando a Fredéric Masson que dizia "o que torna imortal uma nacionalidade não é a sua língua falada: é a sua língua escrita" (idem, p. 230-231), reforça Bilac: "As línguas apenas faladas são sempre derrotadas pelas línguas que, além de faladas, são lidas e escritas" (idem, ibidem).

Entre os tais "perigos estrangeiros" o alemão era o mais temido. Para contê-lo, dizia Alcindo Guanabara, seria necessário "bom exército, boa esquadra e boas escolas" (Gazeta de Notícias, 10/01/1905 in BILAC, 2011, p. 317). Já Bilac acreditava que esses perigos não eram estrangeiros e sim internos, decorrentes de nossas próprias mazelas:

exército e esquadra nada valerão, se não existir, para defender a terra cobiçada, este sentimento, que é mais poderoso do que todas as armas: a consciência da nacionalidade. Não se receia aqui uma invasão à mão armada, que possa ser repelida em batalhas campais ou navais. Nem é isso o que se chama o 'perigo alemão'... A conquista. Se um dia se fizesse, far-se-ia pela absorção pacífica e lenta da nacionalidade brasileira. Levantar-se-ia o povo para repelila? Mas como, se já não houvesse povo brasileiro? - Isto é, se a maioria da população do Sul fosse uma gente falando alemão, escrevendo alemão, não falando, nem escrevendo, nem compreendendo o português? O que forma a nacionalidade é, antes de tudo, a língua. E é a língua que se está perdendo (Gazeta de Notícias, 10/01/1905 in BILAC, 2011, p. 317).

Hoje, claro está que a língua não é o esteio único da nacionalidade e já na época havia um Ernest Renan - que Bilac tinha como leitura de cabeceira - dissertando sobre as especificidades das formações nacionais ${ }^{4}$, também havia as repúblicas vizinhas que tinham de construir suas nacionalidades para além do castelhano - comum a todas elas (RAMA, 1985), mas as unificações de Itália e Alemanha (1871) ofereciam exemplos límpidos de comunidades nacionais aglutinadas em torno da língua, literatura e cultura num espaço de experiência ainda recente para a geração de Bilac.

\footnotetext{
${ }^{4} \mathrm{O}$ texto $O$ que é uma nação? teve origem na conferência Qu'est-ce qu'une nation? dada por Renan na Sorbonne em 1882 e publicada posteriormente no volume Discours et conférences (1887). Uma tradução feita por Glaydson José da Silva pode ser encontrada na Revista Aulas, n. 02, v. 1 - Unicamp, Campinas, p. 87-102.
} 


\section{Um país que não lê}

O ano era 1903, Campos Sales (1841-1913) havia "saneado" as finanças do país através da política de funding loan ${ }^{5}$ e passado o bastão a Rodrigues Alves (1848-1919), a reforma do prefeito Pereira Passos (1836-1913) tomava corpo, derrubando a velha e insalubre cidade, deixando vislumbrar-se uma nova e radiante capital que prometia um futuro triunfante e o jornalista João do Rio (1881-1921) publicava, na Gazeta de Notícias, artigo sobre o movimento das livrarias cariocas. Tributário da excitação do momento, o título era "O Brasil lê", todavia, Bilac apontava que o otimismo de João do Rio chegava a ser ingênuo. "Não, meu caro João do Rio! O Brasil não lê; e não lê pela razão única e terrível de não saber ler" (Gazeta de Notícias, 04/12/1903 in BILAC, 2012, p. 202). Bilac cita números: apenas dois livros da mais famosa e bem sucedida editora brasileira da época, a Garnier, haviam esgotado suas edições em um ano - e as edições da casa geralmente eram de apenas dois mil exemplares. À época, havia também na França uma 'crise do livro', os editores já não vendiam e lucravam como antes, mas como ressaltava Bilac, isso se devia ao crescimento dos jornais. No Brasil, segundo ele, tal paralelo não acontecia já que nenhum jornal do país era capaz de vender cinquenta mil cópias diárias - mesmo aqueles que eram despachados para o país todo. Esse subdesenvolvimento literário decorrente do analfabetismo incomodava o poeta:

A antiga Revue des Revues tem uma seção em que aparece, mensalmente compendiado, o movimento literário do mundo inteiro. Ali se encontra o resumo dos principais artigos das revistas europeias, norte-americanas, chilenas, motevideanas, peruanas. E não há referência a uma só revista brasileira... pela simples razão de que não temos revistas! Justamente o último número da Revue resume um artigo da revista Estudios, de Montevidéu, sobre 'a literatura do Maranhão de 1830 a 1902'. Ficamos sabendo que houve no Maranhão um Antônio Henrique Real, um poeta Otero Mendes, um romancista Sabas da Costa, um poeta Franco de Sá. Ficamos além disso sabendo que Aluísio Azevedo é tradutor de Molière e crítico teatral, e uma série de outras novidades, - numa atrapalhação de nomes, numa confusão de datas, de escolas, de pessoas... De maneira que, condenados a ser conhecidos pelo que de nós escrevem os que não nos conhecem, ainda devemos pedir ao céu, como uma grande esmola, que ninguém procure despir-nos do nosso anonimato, - porque, enfim, mais vale ser desconhecido do que ser caluniado... (Gazeta de Notícias, 11/02/1903 in BILAC, 2011, p. 170-171)

Nesse mar de iletrados que era o Brasil, conclui:

Aqui, os poetas, os romancistas, os críticos, os polemistas escrevem para si mesmos, para os oficiais do mesmo ofício, para o limitado grupo dos profissionais. Nós nos faquirizamos na contemplação do nosso próprio umbigo; nós fazemos literatura como quem se entrega à prática de um prazer egoísta e solitário (Gazeta de Notícias, 11/02/1903 in BILAC, 2011, p. 170-171).

A mesma opinião tinha o gramático, crítico literário e historiador João Ribeiro (1865-1934). Para ele, apenas com muito custo e boa vontade era possível encontrar quarenta homens de letras no

\footnotetext{
${ }^{5}$ Campos Sales assume a presidência em 1898 e com inflação em alta e o preço do café em baixa devido a superprodução. Diante disso, negocia com banqueiros ingleses empréstimos na casa de 10 milhões de libras esterlinas e uma suspensão provisória do pagamento dos juros da dívida externa prolongando os débitos.
} 
Brasil para compor a Academia Brasileira de Letras: "em rigor, se a França tem quarenta acadêmicos, nós não podíamos aspirar a mais do que quatro" (RIBEIRO in LEÃO, 1962, p. 67). Bilac acreditava que o país passava por um momento especial, no qual se verificava um "incontestável adiantamento intelectual e moral” (Gazeta de Notícias, 03/09/1900 in BILAC, 2011, p. 51), contudo, para se ter uma grande nação era fundamental difundir esses avanços entre os setores sociais, não bastava ter uma expertise restrita em termos numéricos.

\section{O Secundário e as Universidades}

Focando na alfabetização e obrigatoriedade na instrução primária, pouco espaço sobrou nas crônicas de Bilac para o secundário e as universidades. Para ele, esses níveis de ensino claramente eram menos importantes, acessórios, pois dependiam da existência da instrução primária. Mesmo assim, em algumas oportunidades o escritor dissertou acerca do assunto e deixa transparecer - mais uma vez - sua crença no poder da legislação educacional para sanar as mazelas do sistema:

Ainda hoje, no Brasil, saber escrever com correção é um luxo inútil para quantos não se querem dedicar à literatura e ao jornalismo. Médicos, advogados, engenheiros timbram em escrever com desmazelo, julgando que a forma apurada, o estilo correto, o amor e o bom trato da língua nacional são nonadas para quem se dedica ao exercício de uma profissão prática. Abre-se (com exceções) a tese de um sextanista de medicina, e fica-se horrorizado e pasmado diante de tantos barbarismos e tamanha obscuridade de expressão. Na França, na Inglaterra, na Itália, não há médico, ou advogado, ou engenheiro, que não saiba escrever com correção a sua língua. Por quê? Porque, na Europa, os estudos normais são obrigatórios, e ninguém se matricula numa escola superior sem haver completado o curso de humanidades em qualquer ginásio ou liceu. Aqui é a calamidade que se vê... (Gazeta de Notícias, 06/02/1902 in BILAC, 2011, p. 138)

A afirmação pode ser entendida como um mea culpa. Afinal, Bilac ingressara no curso de medicina com apenas quinze anos de idade sob autorização especial do Imperador Pedro II. O domínio da língua era essencial no entender de Bilac:

nós pensamos por meio de palavras: e quem não sabe se servir das palavras não pode aproveitar suas ideias. Para ser um bom médico, um bom engenheiro, um bom advogado não é necessário ser um literato: mas é necessário e imprescindível saber falar e escrever (idem, ibidem)

Na mesma crônica, Bilac ainda defende o "tão malsinado, tão caluniado, tão ridicularizado" curso de bacharelado do Colégio Pedro II, pois era o único curso - a seu tempo - que se destinava aos que seguiam no professorado. Cabe esclarecer que se os candidatos às faculdades fossem capazes de passar nos exames de admissão não lhes era exigido diploma do secundário. Assim, grande parte dos alunos do Colégio Pedro II não chegava a o obter o diploma da instituição porque acabavam sendo aprovados nas faculdades antes do término do curso. Com efeito, os que concluíam recebiam o diploma de Bacharel em Ciências e Letras. Esse diploma não tinha uma aplicação prática, não era requisito para nenhum cargo em específico, mas dotava de prestígio seu portador.

Universidades eram representantes da modernidade, da ciência, do progresso, mas Bilac tinha uma visão assaz pragmática, não bastava meia dúzia de experts, não era disso que o país precisava: "Todas as Universidades, todas as reformas do ensino que decretarmos, serão inúteis, enquanto a lei da instrução primária obrigatória não vier trazer a única reforma salvadora" (Gazeta de Notícias, 19/12/1903 in BILAC, 2011, p. 207). Se, como poeta, Bilac 
era o amigo das musas, o representante do parnasianismo no Brasil, enquanto cronista tinha um senso prático bem aguçado no diagnóstico e resolução dos problemas nacionais:

o fim da educação não é preparar eruditos frios, nem sábios secos, nem ideólogos impassíveis, indiferentes às lutas sociais: é preparar homens de pensamento e ação, a um tempo compassivos e enérgicos, corajosos e hábeis, capazes de empregar valiosamente em proveito da coletividade todas as forças vivas da sua alma e todo o arsenal de conhecimentos de que os apercebeu o estudo. Em um país novo como este, onde quase tudo ainda está por fazer, seria absurda e monstruosa a existência de cenobitas do ideal, de anacoretas da ciência, poetas ou filósofos, matemáticos ou artistas, isolados no estudo egoísta, surdos à agitação da existência comum dos homens, insensíveis às sugestões do meio em que vivem. [...] Estudando bem as condições políticas e econômicas da nossa pátria, vereis, meus jovens amigos, que os homens da vossa geração vão receber um honrosíssimo, porém onerosíssimo legado (BILAC, in HANSEN, 2011, p. 26).

Assim, num país novo no qual tudo ainda estava por fazer, as ideias defendidas por Bilac quanto a educação nacional - inserida nessa agenda modernizante de que falamos - chamam atenção pelo senso prático na busca por resolução dos problemas nacionais. Junto do desenvolvimento de sua carreira como cronista, o vemos ampliar seu engajamento em campanhas cívicas - e a alfabetização, pilar da cidadania, estava dentro dessa problemática para ele. Patrícia Hansen (2007, p. 63) aponta que o entendimento do Brasil como país novo, uma criança perante as senhoras europeias, é característica comum a toda literatura cívico-patriótica da Primeira República e esse paradigma só viria a ser abalado por Monteiro Lobato na década de 1920. Portanto, nesse turbilhão de processos e coisas que estavam por fazer, de obras a concluir, Bilac entendia ser a constituição de um país coeso e firmemente unido a tarefa primordial. Mas essa missão não se cumpriria sem uma escolarização maciça da população que seria o duplo esteio da nação, pois na escola se ensinaria as técnicas e saberes - necessários para a vida moderna - e se cultivaria o amor à pátria - sem o qual qualquer ciência seria vã e o país não avançaria.

\section{Tímido progresso}

Em crônica de 1904 (Gazeta de Notícias, 05/04/1904 in BILAC, 2011, p. 237-238) acerca das matrículas escolares na municipalidade do Rio de Janeiro Bilac demonstra otimismo: de 1893 a 1903 o número de matriculados subira de 11099 alunos para 26707. Bilac não se mostrava plenamente satisfeito, porém para alguém que trabalhava como inspetor da instrução pública e sabia "o quanto custa convencer um pai analfabeto da necessidade de dar educação aos filhos" tratava-se de um aumento significativo. Bilac ainda destacava o árduo esforço das professoras que no turno de descanso saíam à caça de alunos e propagandeando as benesses da instrução. Para o poeta, o trabalho das docentes seria facilitado se a instrução primária fosse, como nos "países civilizados", obrigatória. E "se, no dia 15 de novembro de 1899, o Governo Provisório tivesse decretado a obrigatoriedade da instrução primária, nós já teríamos hoje uma imprensa dilatada e um comércio abundantíssimo de livros, porque toda uma geração sabendo ler e escrever, teria brotado do seio dessa lei salvadora..." (Gazeta de Notícias, 08/03/1904 in BILAC, 2011, p. 231).

Jules Ferry tornou a escola laica na França em 1880, no ano seguinte implanta o ensino primário gratuito e em 1882 decreta sua obrigatoriedade completando o tripé da escola pública à francesa - gratuita, laica e obrigatória. Anos depois, em visita a Paris, Bilac podia ver os efeitos de tal medida. "Para quem vive mais pela vida do cérebro do que pela vida grosseira dos 
sentidos é uma satisfação encantadora verificar que não há talvez, nesta grande Paris, uma só criatura adulta que não saiba ler" (Gazeta de Notícias, 15/06/1904 in BILAC, 2011, p. 257) e põe-se a narrar um dia comum da brilhante e letrada cidade:

De manhã, todas as costureirinhas pobres, que vão, à pressa, a caminho do atelier, comendo um croissant, que é quase sempre todo seu almoço; todos os carregadores, criados, cocheiros, condutores de caminhões; todos os operários, de blusa e bonet, que marcham para o ar confinado das oficinas; todas as cozinheiras e todas as criadas de servir: - todos os burgueses, que enchem os ônibus, os tramways, os carros do chemin de fer de ceinture; - toda essa gente passa com um jornal na mão, levando para o trabalho a sua ração de alimento intelectual. O jornal entra na mais pobre água-furtada, no mais humilde casebre: e todos sentem aqui a necessidade de nutrir o cérebro (Gazeta de Notícias, 15/06/1904 in BILAC, 2011, p. 257-258).

A escolarização das massas e desenvolvimento da indústria dos impressos ocorridos na França, aliados ao alto nível de sua literatura - para não falar das elegâncias de Paris - servia como modelo de Civilização - polida e letrada - que deveríamos seguir. Mas essa ideia não ganhava campo apenas no Brasil, conforme ressalta Jean-François Botrel (2012, p. 62-67) ela foi comum a quase todos os países ocidentais, esteve presente no México e em toda América do Sul e também na Espanha e Portugal.

Já o Brasil, na percepção do cronista, apenas engatinhava na alfabetização das massas e à duras penas obtinha tímidos progressos. Ainda que a cena descrita acima sobre Paris possa ter sido um pouco romanceada, devemos entender a preocupação de Bilac em difundir um projeto educacional massivo, de amplitude social. O pilar de um país moderno era o letramento da população, sem isso não haveria consciência nacional, não haveria universidade, nem indústria, nem ciência e, muito menos, espaço para os escritores:

Temos uma Academia de Letras, com quarenta escritores (?) consagrados (!) e imortais (!); mas, num país que conta vinte milhões de habitantes, nem um só desses escritores conseguiu viver exclusivamente do seu trabalho artístico, e nem um só dos seus livros logrou jamais alcançar uma tiragem de dez mil exemplares! E, afinal, é com absoluta e plena razão que os inimigos da Academia perguntam qual é a utilidade desse concílio permanente de gênios mais ou menos inéditos e desconhecidos (Gazeta de Notícias, 13/11/1905 in BILAC, 2011, p. 366).

A crítica de Bilac à cidadela letrada é contundente. O país não precisava de sábios enclausurados em suas torres de marfim e não se tratava, apenas, de uma busca por ampliação de público leitor e sim de desenvolvimento social. De nada valiam, também, as universidades que ao lado da Academia perpetuava uma ilustração fútil:

Se da totalidade da nossa população, uma quinta parte estivesse familiarizada com os segredos do alfabeto, já os escritores teriam um imenso público. Mas os escritores não têm público pequeno ou grande, - porque no Brasil, em vez de ter escolas primárias, tem Universidades, - e uma Academia, que, neste país de analfabetos, representa o mesmo triste papel de um cinematógrafo numa casa de cegos ou de um fonógrafo numa de surdos: um luxo inútil e ridículo. Um ironista dizia, 
há dias: 'A Academia tem uma razão de ser: como não há público que leia os acadêmicos, eles leem-se uns aos outros' (Gazeta de Notícias, 13/11/1905 in BILAC, 2011, p. 367).

Dentro de alguns anos, a luta de Bilac foi recompensada - ainda que modestamente. Se os indicadores sociais gerais de educação continuavam desoladores, ao se olhar exclusivamente a ampliação da instrução pública podia-se ver algum avanço:

O progresso realizado nesses últimos dez anos é admirável. A Escola Pública levantou-se, regenerou-se, nobilitou-se a tal ponto, no Rio de Janeiro, que as melhores e as mais ricas famílias da cidade, abandonando o ridículo preconceito segundo o qual tudo quanto é gratuito é mau, já lhe dão, para a primeira educação dos filhos, a preferência antigamente dada aos colégios particulares que tinham apenas o mérito de ser particulares e... caros. Esse progresso da Escola Pública é devido - nem é necessário dizêlo - ao progresso do estudo normal. Até Calino é capaz de afirmar que não pode haver boas escolas sem bom professorado (Gazeta de Notícias, 27/09/1906 in BILAC, 2011, p. 407).

No tocante ao magistério, Bilac referia-se a formação das primeiras egressas da Escola Normal do Rio de Janeiro em 1906. Além de avançar na formação de professores, o país caminhava na melhora dos seus indicadores desde o fim do século XIX. Se ainda não se podia celebrar a massificação da escola e da alfabetização, estava em curso o crescimento da população estudantil tanto em números absolutos quanto percentuais e, paralelamente, $\mathrm{o}$ desenvolvimento de uma literatura infantil-escolar destinada aos estudantes das primeiras letras que aproveitava o crescimento do público leitor ${ }^{6}$ e teve em Bilac um dos seus mais célebres autores. Sobre esses tímidos progressos, Marisa Lajolo aponta que:

Nos primeiros anos do século XX, o país apostava em si mesmo: acreditava ter superado impasses econômicos e sociais com a extinção da mão de obra servil em 1888, e no campo das instituições a República também parecia ter realizado as promessas de modernidade, embutindo em si o futuro (LAJOLO in BILAC \& BOMFIM, 1996, p. 15)

Em 1902, Bilac publica a versão definitiva de seu livro Poesias e daí em diante observase a diminuição dos seus trabalhos como poeta, sua consolidação como cronista, o crescimento de seu engajamento em campanhas públicas e de seus escritos para crianças. É preciso dizer que concomitantemente às crônicas que escrevia para a Gazeta de Notícias, estreia a coluna do mesmo gênero intitulada Registro no vespertino A Notícia; em 1904 assume a função também na novíssima e moderna Revista Kosmos. Seu trabalho na Instrução Pública do distrito federal inicia-se em 1899, onde ocuparia o cargo de inspetor desde a nomeação ao fim da vida.

Sua obra como autor didático-infantil tem início com Contos Pátrios em 1894. Esse livro é fruto dos apuros financeiros que enfrentava Bilac na ocasião: recorrendo ao amigo Coelho Neto, na tentativa de evitar o leilão de joias de sua mãe que ele havia penhorado, encontram a solução ao oferecerem um livro (inexistente no ato) ao editor Francisco Alves. Levantaram quatro contos de réis ${ }^{7}$ (4:000\$000) com a obra que foi escrita em menos de uma semana e vendeu mais de cem mil cópias

\footnotetext{
${ }^{6}$ Era um crescimento típico de fenômenos em estágios iniciais - algo como uma progressão 1-2-4-8 - que dobra num tempo relativamente curto, mas não constitui percentagem relevante perante o total da população.

${ }^{7}$ A moeda corrente da época era o mil-réis, mil mil-réis ou "um milhão de réis" era popularmente chamado de "conto de réis".
} 
até a década de $1920^{8}$; as parcerias foram comum nessa esfera, mais tarde (1905) veio a publicação do Tratado de Versificação (em parceria com Guimarães Passos) e só aumentariam com o tempo, principalmente após o rompimento com a imprensa em 1908: Através do Brasil, possivelmente seu livro mais célebre nessa seara, é publicado em 1910 em coautoria com Manoel Bomfim. No ano seguinte, viria a lume A Pátria Brasileira novamente junto de Coelho Neto.

Se, evidentemente, sua obra como poeta já fora suficiente para notabilizar Bilac entre o público e a casta dos altos letrados, no início do século XX ele se consagraria para além do mundo escrito e impresso. Em 1900, acompanhando como jornalista a comitiva presidencial brasileira em visita a Buenos Aires, Bilac fortuitamente assumiu grande destaque em um dos jantares bilaterais e daquela noite em diante seria convidado a discursar muitas outras vezes: "que hable Bilac, que hable!” (JORGE, 1992, p. 214). Em 1906 é nomeado secretário geral da III Conferência PanAmericana e impressiona Joaquim Nabuco pela sua perfeita oratória. Nesse mesmo ano publica o volume Conferências Literárias, que reunia em livro uma série de palestras que ele havia dado naqueles anos e sempre com muita participação de público ${ }^{9}$. Em 1908 seria o jornalista oficial da Exposição Nacional - evento destinado a apresentar a metamorfose do Rio de Janeiro -, e no ano seguinte, foi convidado a discursar na inauguração do Teatro Municipal do Rio de Janeiro.

Partícipe ilustre desse peculiar processo de modernização do país, não seria exagero marcar seu engajamento pela fórmula Pátria, Civilização e Trabalho que deitaria raízes no nosso ensino como bem demonstrou Circe Bittencourt ${ }^{10}$ e serviu de fio condutor a trama de Através do Brasil.

\section{Considerações Finais}

As crônicas aqui exploradas revelam as linhas mestras de Olavo Bilac enquanto publicista. Em paralelo, temos também sua literatura cívico-patriótica destinada as primeiras letras - dentro e fora da escola - que se coaduna a esse ideário e, em certa medida, revela a precariedade das letras nacionais à época: o poeta que vira cronista, o cronista que vira alfabetizador das massas.

Essa polivalência não foi exclusividade de Bilac, era a regra geral do período, sobretudo no Brasil (MACHADO NETO, 1973; MICELI, 1977). A crescente especialização e ramificação das ciências e segmentação do mercado livreiro que andava a passos largos na Europa demoraria a se estabelecer abaixo do Equador e as crônicas que aqui analisamos deixam entrever tanto a diferença do mercado nacional das letras perante o europeu, quanto a necessidade de desenvolvê-lo.

O desenvolvimento incerto e peremptório do pequeno mundo das letras no Brasil inseria-se num projeto mais amplo de modernização a qualquer custo levado a cabo pelas elites republicanas. No entanto, se hoje nos parece claro que a inserção no Brasil na Belle Époque não foi pacífica, nem se deu sem dissabores, devemos atentar a proliferação de sentidos e projetos que se aglutinavam em torno de palavras-chave como República, Modernidade, Instrução.

Pertencente a uma expertise cosmopolita e viajada Bilac partilhava e defendia esses ideais que se alastravam pelo globo na velocidade dos vapores. No entanto, claro está que esses ideais foram subvertidos e explorados pelas antigas elites sendo a República o maior exemplo.

Nesse sentido, devemos entender o Bilac cronista não como defensor cínico dos projetos das elites e sim um defensor - com suas idiossincrasias, preferências e oscilações - dos valores originais esboçados pelo movimento republicano que via na alfabetização massiva da população o passaporte para uma cidadania efetiva na moderna civilização.

\footnotetext{
${ }^{8}$ Esta história foi contada pela primeira vez por Humberto de Campos (1886-1934) em seu Diário Secreto (1954) e é respalda por Jorge (1992); Machado Neto (1973); Miceli (1977) e Hallewell (2005).

${ }^{9}$ Brito Broca (2004, p. 194) aponta a popularidade de Bilac como uma das estrelas das conferências literárias que era moda na primeira década do século XX e nas quais se cobrava dois mil-réis como ingresso.

${ }^{10}$ BITTENCOURT, Circe. Pátria, Civilização e Trabalho - O Ensino de História nas Escolas Paulistas (19171939). Edições Loyola: São Paulo, 1990.
} 


\section{Referências}

ARROYO, Leonardo. Olavo Bilac. São Paulo: Edições melhoramentos, 1952.

BILAC, Olavo. Registro - crônicas da Belle Époque carioca. Org. Alvaro Santos Simões Jr. Campinas: Editora Unicamp, 2011.

BILAC, Olavo. Vossa insolência: crônicas. Org. Antônio Dimas. São Paulo: Companhia das Letras, 1996.

BILAC, Olavo \& BOMFIM, Manoel. Através do Brasil. São Paulo: Companhia das Letras, 2000.

BOTREL, Jean-François. Impressos sem fronteiras no século XIX (França, Espanha, América Latina) in GUIMAR ÃES, Valéria (org). Transferências culturais - o exemplo da imprensa na França e no Brasil. Edusp/Mercado das letras: São Paulo/Campinas, 2012

BROCA, Brito. A vida literária no Brasil - 1900. José Olympio/ ABL: Rio de Janeiro, 2004.

HALLEWELL, Laurence. O Livro no Brasil - sua história. EDUSP: São Paulo, 2005.

HANSEN, Patrícia. Brasil, um país novo: literatura cívico-pedagógica e a construção de um ideal de infância brasileira na Primeira República. Tese de doutorado em História Social FFLCH-USP: São Paulo, 2007.

HANSEN, Patrícia. Infância como projeto. Nacionalismo, sensibilidades e etapas da vida em Olavo Bilac. Anais do XXVI Simpósio Nacional de História - ANPUH: São Paulo, 2011.

HEIZER, Alda \& VIDEIRA, Antonio (org). Ciência, civilização e república nos trópicos. Rio de Janeiro: Mauad X/ FAPERJ , 2010.

JORGE, Fernando. Vida e poesia de Olavo Bilac. $4^{a}$ edição. São Paulo: T.A Queiroz, 1991.

LEÃO, Mucio. João Ribeiro. Livraria São José: Rio de Janeiro, 1962

MACHADO NETO, Antônio Luís. Estrutura Social da República das Letras: sociologia da vida intelectual brasileira 1870-1930. EDUSP: São Paulo, 1973.

MICELI, Sérgio. Poder, Sexo e Letras na República Velha (estudo clínico dos anatolianos). Perspectiva: São Paulo, 1977.

MOLLIER, Jean-Yves. A leitura e seu público contemporâneo - Ensaios sobre História Cultural. Autêntica: Belo Horizonte, 2008.

NEEDEL, Jeffrey. Belle Époque Tropical. Cia das Letras: São Paulo, 1992.

RIO, João do. O Momento Literário. Versão Digital - Fundação Biblioteca Nacional: Rio de Janeiro, 1905.

SCHWARCZ, Lilia. (dir) História do Brasil Nação: 1808-2010 - Volume III “A Abertura para o Mundo 1889-1930”. Objetiva: Rio de Janeiro, 2012.

SEVCENKO, Nicolau. Literatura como Missão: tensões sociais e criação cultural na Primeira República. Ed Brasiliense: São Paulo, 1999. 